\title{
International Perspectives on Intersecting Engineering's Grand Challenges and the UN's Sustainable Development Goals
}

\section{Dr. Christina Kay White, Massachusetts Institute of Technology}

Dr. Christina White is currently a postdoctoral engineering education research associate with SingaporeMIT Alliance for Research and Technology (SMART) Innovation Centre. She completed her Doctoral degree from Teachers College, Columbia University where she studied engineering education. She is the Global Chair and founding director of the National Academy of Engineering Longhorn Grand Challenges Scholars \& K12 Partners Program at The University of Texas at Austin. Dr. White is also the director of an outreach program called Design, Technology, \& Engineering for All Children (DTEACh) which has reached more than 1000 teachers and 85,000 students. She is the lead inventor on a patent for assistive technology. Her current research includes global competencies, innovative design-based pedagogy, humanitarian engineering, and ways to attract and retain traditionally underrepresented groups in engineering education.

\section{Dr. Renetta G. Tull, University of Maryland, Baltimore County}

Dr. Renetta Garrison Tull is Associate Vice Provost for Strategic Initiatives at the University of Maryland, Baltimore County (UMBC: An Honors University in Maryland). She serves Professor of the Practice for the College of Engineering and Information Technology, and is part of the Engagement Team. She is also on detail with the University System of Maryland (USM), where she is Special Assistant to the Senior Vice Chancellor for Academic Affairs, and Director of Pipeline Professional Programs for the system's 12 academic institutions. She is the Co-PI and Founding Director for the National Science Foundation's PROMISE: Maryland's Alliance for Graduate Education and the Professoriate (AGEP), and Co-PI for the Louis Stokes Alliance for Minority Participation (LSAMP) and Bridge to the Doctorate programs for the USM. Dr. Tull serves on a number of boards for women and diversity in STEM initiatives throughout the US and in Latin America. She is Vice President of Initiatives for the Latin and Caribbean Consortium of Engineering Institutions (LACCEI), and co-leads the "Women in STEM" initiatives for the organization. As a former professor at the University of Wisconsin-Madison, her engineering and speech science research covered topics of accessibility. Her current research in Maryland looks at intersections of social science theories, STEM equity, and physics. She was a "Cover Girl" for O'Reilly Media's "Women in Data" issue in 2015, a finalist for the 2015 Global Engineering Deans Council/Airbus Diversity Award, Sci Chic/Medium.com 35 "Women STEM on Social Media Stars" (July 1, 2016), and 2016 winner of the Claire Felbinger Award for Diversity from ABET. She is a Tau Beta Pi "Eminent Engineer," and can be found online @Renetta_Tull and https://renettatull.wordpress.com/.

\section{Dr. Yevgeniya V. Zastavker, Franklin W. Olin College of Engineering}

Yevgeniya V. Zastavker, Ph.D., is an Associate Professor of Physics at Franklin W. Olin College of Engineering. She earned her B.S. degree in Physics from Yale University in 1995 and her Ph. D. degree in Biological Physics from MIT in 2001. Dr. Zastavker's research interests lie in the field of STEM education with specific emphasis on innovative pedagogical and curricular practices at the intersection with the issues of gender and diversity. Dr. Zastavker is currently working with Dr. Stolk on an NSF-supported project to understand students' motivational attitudes in a variety of educational environments with the goal of improving learning opportunities for students and equipping faculty with the knowledge and skills necessary to create such opportunities. One of the founding faculty at Olin College, Dr. Zastavker has been engaged in development and implementation of project-based experiences in fields ranging from science to engineering and design to social sciences (e.g., Critical Reflective Writing; Teaching and Learning in Undergraduate Science and Engineering, etc.) All of these activities share a common goal of creating curricular and pedagogical structures as well as academic cultures that facilitate students' interests, motivation, and desire to persist in engineering. Through this work, outreach, and involvement in the community, Dr. Zastavker continues to focus on the issues of women and minorities in science/engineering.

Ms. Rovani Sigamoney, UNESCO

(c)American Society for Engineering Education, 2018 


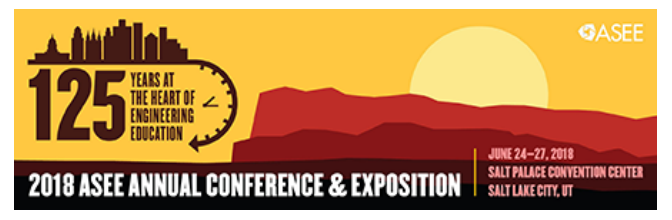

Rovani Sigamoney is a chemical/environmental engineer from South Africa who started in the platinum refinery/mining sector and then moved on to researching bioenergy systems and biofuels for Africa.

She joined the United Nations Educational, Scientific and Cultural Organisation (UNESCO) HQ in Paris, France in 2007 and later ran the Chemistry programme and International Year of Chemistry 2011 and thereafter the Engineering programme. The Engineering Programme is working with countries, international partners and program experts to strengthen engineering education through curricula development, hands-on training and capacity building. In line with UNESCO's global priorities on Africa and Gender Equality, it focuses on women and Africa. Rovani is passionate about women in engineering and encouraging more youth to pursue careers in engineering.

She previously worked at the United Nations Environment Programme (UNEP), Paris on a biofuels strategy and also at the Wuppertal Institute of Climate Change in Germany on a policy document for the European Parliament on the security of energy supply. 


\section{International Perspectives on Intersecting Engineering's Grand Challenges and the UN's Sustainable Development Goals}

\section{Introduction}

Growing complexity and magnitude of the challenges facing humanity require new ways of understanding and operationalizing solutions for more healthy, sustainable, secure, and joyful living. Developed almost contemporaneously but separately, the National Academy of Engineering's 14 Grand Challenges (GCs) and United Nations' 17 Sustainable Development Goals (GCs) describe and call for solutions to these challenges. During the 2017 meetings for the United Nations Educational, Scientific and Cultural Organization (UNESCO) Kick-off for Engineering Report II in Beijing, the Global Grand Challenges Summit in Washington, DC, and the World Engineering Education Forum (WEEF) in Malaysia, our team sought to expanded our work to include international perspectives on ways that the GCs and SDGs could be more strongly connected and the ways in which next generation global workforce may be better prepared to address both GCs and SDGs.

Within this context we ask, "How can educators integrate best practices to nurture and support development of globally competent students who will reach the goals as the Engineers of 2020?" and "How can connectivity and alignment of curricula to the GCs and SDGs foster students' development?"

Conclusions from UNESCO's meeting were that educators and stakeholders still have much to do with respect to sharing the 17 SDGs with engineering audiences around the world. This conclusion was reiterated at WEEF when an informal poll among participants from around the world revealed that knowledge of both the GCs and the SDGs was not as wide-spread as we had initially assumed. There were several engineering educators who were learning about both of these constructs for the very first time. This led to concerns posed by students participating in the Malaysia conference as part of the Student Platform for Engineering Education Development (World SPEED). The student teams from India, Colombia, Brazil, and Korea acknowledged potential disadvantages associated with learning in the environments created by educators unequipped with knowledge of topics covered by the GCs, and the SDGs. The students were further concerned that their faculty and mentors would not be able to create educational environments that allow for development of intentional learning and conscientious projects associated the GCs and SDGs.

To this end, this report discusses ways that the GCs and SDGs are driving international conversations about engineering curricula, diversity and inclusion, and partnerships for the goals and proposes new venues that may offer opportunities for further explicit integration of GCs and SDGs into engineering education worldwide. 


\section{GCs and SDGs: Considerations for Integrating Liberal Arts and Engineering}

As world citizens, we all face challenges pertaining to the energy, education, water, and shelter. Humanitarian engineering experiences and design can provide people with some of the tools to responsibly address these pressing problems. Millions of people contend with considerable challenges due to limited essential resources that humanitarian engineering addresses in an effort to actively engage people in participatory democracy and promote social justice for citizens of our world $[1,2,3,4,5,6]$.

From drinking straws that protect against waterborne diseases, to solar-powered incubators, to assistive educational technology, to environmentally-safe temporary housing for hurricane survivors, humanitarian engineering designs are prime examples of interventions which act locally to create possibilities of life-changing opportunities by: (a) breaking cycles of poverty and inequities through education, (b) ameliorating detrimental health conditions and addressing issues of limited food and access to clean water, (c) creating alternatives to inadequate shelter, (d) and reconsidering innovative alternatives for deficient energy conditions all of which have been endured by a large proportion of the world population for hundreds of years [7].

One of the ways that engineering is situated is the National Society of Professional Engineer ethics creed (1954) [8] stating “...I dedicate my professional knowledge and skills to the advancement and betterment of human welfare." Like many other professional society ethics statements, engineers identify service to humankind as their greater purpose. In other words, social responsibility lies at the core of the engineering profession. The social responsibility of engineers is to carefully evaluate the full range of broader impacts of their designs on the health, safety, and welfare of the public environment. Half a century after the creed originated, our world is facing irreparable damage and destruction that has direct connections to and repercussions from the consequences of engineering. More specifically, there was and continues to be a lack of comprehensive engineering assessment of the societal, ethical, health and safety, environmental, political, and sustainability issues and a lack of systems thinking [9] that can be addressed with research $[7,10,11]$.

Although not everyone will become an engineer, we all will need problem-solving and negotiation experience, tolerance for ambiguity, an understanding of systems thinking, and at least basic STEM literacy to be an active participant in making decisions about communities in our world $[7,10,12]$. Democratic practices are ways that we are a community in the making [13]. Exploring democratic practices in engineering education allows for understanding of the power structures and opportunities for decision-making. As such, it is critical that the next generation workforce has a critical understanding of engineering to enable decision-making about how to interact with and make choices about the natural and engineered world around us. Participation is a key component in the concept of democracy. To be fair, a number of STEAM 
(Science, Technology, Engineering, Arts, and Mathematics) programs have been appearing in the last few years to create explicit connection between STEM and Arts or STEM and Humanities at both the K-12 and Higher Ed levels (e.g., the University of Rhode Island's NSF EPSCOR and RISD's STEM to STEAM initiative, as well as new programming at Georgia Tech, University of Iowa, the State University of New York at Potsdam, etc.) [14]. In addition, a number of initiatives related to citizen science projects have been making their way into the mainstream of both K-12 and Higher Education (e.g., $[15,16])$. These individual efforts are impressive; however, they are localized and they miss the mark on creating a united front to educate the next generation workforce prepared to tackle the problems facing the world today and certainly tomorrow. In fact, to our knowledge, NAE's Grand Challenges and the associated Grand Challenges Scholars Program (GCSP), as described below, is the only effort that provides a framework and the language around the ways in which we can support development of our students to be prepared to tackle challenges described in GCs and SDGs.

\section{Connecting the Grand Challenges and the Sustainable Development Goals}

Upon reflection on the 20th century and forward looking to our first decade of the new millennium, the National Academy of Engineering (NAE) sought innovative ways to identify formidable challenges as the global population continues to grow and its needs and desires continue to expand. The NAE garnered a team of leading thinkers to explore broad realms of human concern - sustainability, health, vulnerability, and joy of living - and they generated 14 complex Global Grand Challenges that await engineering solutions. Recently, the United Nations (UN) adopted Sustainable Development Goals (SDG) to significantly improve the lives of the world's citizens [17] - [26]. We hypothesize that the Global Grand Challenges and the Sustainable Development Goals have common stakeholders that engage in and are impacted by university-based strategic thrusts. In this paper, we conduct a review of literature about major initiatives that address grand challenges across several disciplines so that we can help visualize a landscape of these initiatives including where and how the NAE Global Grand Challenges and the UN Sustainable Development Goals intersect. We describe the design and initial phases of our pilot study, through which we seek to understand potential intersectionality of the Global Grand Challenges and Sustainable Development Goals as well as participation in addressing these complex issues through experiential learning [25]. Although in its preliminary stages, and more descriptive rather than analytical in nature, this paper is meant to serve as a conversation starter between multiple stakeholders about the ways in which we may come together as a community of practice to create an environment which best supports education of the next generation workforce prepared to tackle problems described by GCs and SDGs. As well, this paper serves as a call for the national and international organizations (e.g., ASEE, ABET, ENAEE, etc.) to come together with local and governmental agencies as well as student- and citizen-driven initiatives (e.g., Engineers for a Sustainable World or Engineers Without Borders)

to address the objectives of GCs and SDGs.) 


\section{Global Venues Bringing Attention to the GC-SDG Intersections}

In 2009, shortly after the NAE identified the Grand Challenges, academic leaders designed a cocurricular framework, NAE Grand Challenges Scholars Program (GCSP) to integrate into engineering programs so that students and educators could engage in effective ways of exploring and engaging with the Grand Challenges. Shortly thereafter, Grand Challenges Scholars Programs (GCSP) have started in a wide range of universities. All students who are recognized as Scholars apply five key components of the GCSP to face the Grand Challenges with (1) business/entrepreneurship; (2) social consciousness; (3) multicultural mindset; (4) hands-on research; and (5) multi-disciplinarity.

In the last year, world leaders came together in a historic United Nations Summit and adopted Sustainable Development Goals (SDG). The SDGs build on the foundation and success of the Millennium Development Goals and aim to go further to ameliorate poverty. These SDGs call for action by all countries and all income levels to promote prosperity while protecting the planet by considering issues of sustainability and resilience. They recognize that the goal of ending poverty must incorporate strategies that build economic growth while addressing a range of social needs including education, health, social protection, and job opportunities, as well as tackling climate change and environmental protection.

In July 2017, the GC Global Summit in Washington D.C. brought together an international collection of educational, industrial, and other organizations interested in engineering education and committed to positively impacting global development and socio-economic growth. The discussion of GCs and SDGs has continued to take flight, and several organizations around the world have engaged in conversations to bring more awareness to to both sets of ideals.

In September 2017, UNESCO convened the Kick-off Meeting for their "Engineering Report II" in Beijing, People's Republic of China. The meeting was co-sponsored by the International Centre for Engineering Education (ICEE), under the auspices of UNESCO (Category 2) based at Tsinghua University in Beijing. The center has been affirmed by the president of the Chinese Academy of Engineering. Content of the meeting included discussion of engineering's contribution to achieving the Sustainable Development Goals (SDGs). Several disciplines can be involved with plans to achieve outcomes related to the SDGs, however, participants in this meeting were particularly interested in how engineering students and professionals could engage, and which of the SDGs might be most relevant for the engineering community to consider. Discussions included issues of diversity and inclusion in engineering, women in engineering, youth engineers and their role, engineering education for the future, and developing "The Future Engineer" and assisting the next generation with adapting to a changing society. The discussions had input from delegations and representatives from the UNESCO (Paris, Jakarta, Beijing), China Association of Higher Education, Chinese Academy of Engineering, World Council of Civil Engineers (WCCE), International Federation of Engineering Education Societies (IFEES), 
the World Federation of Engineering Organizations (WFEO), the Aalborg Centre for Problem Based Learning in Engineering Science and Sustainability under the auspices of UNESCO' (The UNESCO Aalborg Centre) and based at Aalborg University in Denmark, Tsinghua University and the ICEE. Universities such as Nankai University in Tianjin, China; Beijing Jiaotong University in Beijing, China; the University of Maryland Baltimore County (UMBC) in the United States; and the University of Strathclyde in Glasgow, Scotland.

Part of the discussion in Beijing for Engineering Report II included the desire to look at capacity building in engineering and ways that exposure to the SDGs might influence student enrollment and retention in engineering. Of particular interest was considering use of the SDGs to stimulate interest in engineering among women and girls, and people from underrepresented groups participating in engineering. Starting with women and girls, questions such the following were raised:

- How many females are in engineering programs within the regions, and what kinds of data can we use to answer the question?

- How does the participation in engineering among females compare to the population within the regions?

- Are female students within the regions involved with efforts that speak to the SDGs, or similar aspects, e.g., Courses, Capstones, Global Student Forum, Grand Challenge Scholars?

- Are female engineering graduates staying in engineering and contributing to the workforce?

To understand how these various venues work together towards a single goal of addressing global challenges and the ways in which international educators may come together to create holistic experiential curricula to prepare our graduates to solve these challenges, we are in process of conducting this survey with the international thought leaders and are conducting interviews with some of the Summit participants to learn their perspectives on the intersections of the Grand Challenges and the Sustainable Development Goals [27].

\section{Methods}

We hypothesize that the Global Grand Challenges and the Sustainable Development Goals have common stakeholders that engage in and are impacted by university-based strategic thrusts. We seek to understand potential intersectionality of the Global Grand Challenges and Sustainable Development Goals as well as participation in addressing these complex issues through experiential learning. To this end, we will investigate: 


\section{1) How do the Global Grand Challenges and Sustainable Development Goals intersect?}

2) What are diverse perspectives of the intersections of the Global Grand Challenges and Sustainable Development Goals and how does experiential learning impact those perspectives?

To investigate these research questions, we will collect three types of data. First, we conduct a review of literature to determine research and programs that identify and address grand challenges in a range of disciplines. There has not been a mapping of grand challenges across disciplines and so that data are an important part of our study. The other two types of data we are collecting are through a brief survey and semi-structured interview of some of the survey participants. For this paper, we are piloting our survey and semi-structured interviews of diverse stakeholders. This will indicate current engagement in GC and SDG to create visual representation of how these two initiatives intersect.

\section{A. Theoretical Framework}

We will approach this pilot study of our mixed methods research with grounded theory so that the theoretical framework will arise from the data collected through surveys and interviews. We anticipate that it may be helpful in the future to frame our study within a critical feminist theoretical perspective because framing the research questions, design, and analysis within a critical feminist framework means that we could explore and unpack aspects of power structures, voices (not) heard, and participant engagement.

\section{B. Conceptual Framework}

We use the theory of experiential learning to conceptually frame our understanding of the ways that students engage in learning that addresses the intersections of GCs and SDGs. The experiential learning theory is a learning cycle that includes the dual dialectics of action/reflection and experience/abstraction. These two dimensions define a holistic learning space wherein learning takes place between the individual and their environment. Through the pilot interviews, we will identify and analyze ways that GCSP Scholars engage in actions to face the GCs and SDGs and how their experiences and reflections impact their learning and future participation.

\section{Participants}

The online survey will be disseminated through the following networks: NAE GCSP and their K12 Partner Programs, GC Summit attendees, the Student Platform for Engineering Education Development (SPEED), the International Federation of Engineering Education Societies (IFEES), United Nations Education, Science, and Community Organization (UNESCO), the 
Latin American and Caribbean Consortium of Engineering Institutes (LACCEI), members of the Science and Technology in Society Forum (STS Forum), and the Global Engineering Deans Council (GEDC). Our goal for the pilot survey is to collect responses from at least $15 \%$ of each of the networks listed above so that our $\mathrm{N}$ is over 100 participants. We will plan to interview five people from each of the networks for the pilot study.

\section{Data Collection}

\section{A. Learning the Landscape of Global Grand Challenges}

We did an extensive review of global initiatives that hail from a wide range of disciplines, policies, and foundations. We conducted the search through research in international peerreviewed journals, online forums, foundation websites, and policy white papers. We did initial searches of "grand challenges" and also of key terms that are integrated in the NAE Grand Challenges and the UN SDG vernacular such as, "sustainability," "health," "vulnerability," and "poverty." We searched not only for global initiatives but also explored if any of those global initiatives included specific academic, comprehensive co-curricular components such as the GCSP does with the 5 components (research, multidisciplinarity, entrepreneurship/business, social consciousness, and multicultural mindset).

\section{B. Pilot Survey}

We created an online, anonymous survey hosted on Qualtrics to garner insights from diverse stakeholders around the world. Since the GCs and the SDGs are indeed global issues, it is imperative to collect data from a wide range of people. We created a survey that collects voluntary demographic data, including geographic location, age, gender, and school-related identity (e.g., K-12 student, college student, educator, faculty) and their initial alignment of the GCs with the SDGs.

We initially designed the pilot of this survey so that participants can align each of the 14 GCs with any/all of the SDGs that align through drop-down menus. We anticipated that the analysis of this alignment will create a visual of the intersections and will also provide us with information that we can go into more detail during the semi-structured interviews.

In conducting the pilot survey with the STS Forum participants, it became evident that the design of the survey needed to be tested and modified from the original design of the drop-down menu. Based on the feedback from the participants with the pilot, we determined that there are three main ways that participants expressed their ideas of alignment of the GCs and SDGs. The first way is to indicate the alignment on a matrix which is the original design of the survey question. The second way that participants showed alignment was through grouping the SDGs within the 
four main themes of the GCs which are: Sustainability, Health, Security, and Joy of Living. The third way that participants expressed alignment was through a matrix but with the addition of a Likert scale to show the level of alignment that includes: Not Aligned, Aligned, or Strongly Aligned.

Based on the pilot survey feedback, the research team is redesigning the online survey to ask participants to complete the matrix with Likert scale options and secondly to group the SGD into the four themes of the GC.

\section{Pilot Focus Groups and Interviews}

Our research team conducted a focus group discussion during a Special Session for the Grand Challenges at the WEEF 2017. The participants engaged in small group discussions about the intersections, ways that experiential learning impacts student engagement in GCs and SDGs, and also perspectives about those GCs and SDGs that do not intersect to consider other opportunities for future work. The research team identified WEEF 2017 participants who are interested in continuing in the study by participating in interviews in the coming months.

Our research team will conduct these interviews in person or online through free video conferencing. We will provide the participants with our topics for the semi-structured interview and remind them that all answers and participation is voluntary, anonymous, and confidential. We will remove any personal identifiers from the interviews so that the data is anonymous before it is shared with the research team and then the public.

As a research team, we will use purposeful sampling of the networks listed above to invite diverse stakeholders to participate in a short interview to complement the survey findings. The purposeful sampling is in an effort to include a wide range of perspectives of students, educators, and community members as we aim to share diverse perspectives instead of tapping into homogeneous populations of participants. We do this purposeful sampling by interviewing participants from each of the different networks and making sure that the demographics from those groups is also diverse.

These pilot interviews include asking the participants to indicate alignment of the 14 GCs with any/all of the SDGs in a different format than-previously done in options from the survey. By asking the participants to indicate alignment in their own way, the interview participant may offer new ideas about ways to show intersections differently than our research team would have imagined on our own. This empowers the participants to share their own ways of knowing and communicating. We use grounded theory for this pilot and that allows us to be open-minded during the analysis of the participants' alignment data since we do not yet know what formats 
they will produce. After we collect the data and begin analysis as a research team, we will determine how we can code for themes or visually represent the information.

We conceptually frame this study with experiential learning theory. This conceptual framework helps structure the second part of the interview where we explore the participants' learning cycle as it pertains to the GC and/or SDG. Specifically, we ask them to share their real world experiences and reflections. For this qualitative aspect of the study, we will use thematic coding of the responses to identify themes when we analyze the interview data. Since this is our pilot, we will be able to determine how to refine our questioning and analysis procedures for the larger study.

\section{Early Results and Discussion}

We conducted a robust review of initiatives in global grand challenges that spans the last two decades and have created a timeline as a way to visualize part of the landscape. A key finding from the review of global initiatives is that the GCSP is the only co-curricular, university-based initiative with specific components for students and faculty across schools and counties to research, take action, and reflect on addressing these complex issues. We are currently collecting data for our pilot survey and interviews. We are taking the feedback from the pilot to inform the design of methods we will use to conduct this research with the NAE GCSP and their K-12 Partner Programs, GC Summit attendees, the Student Platform for Engineering Education Development (SPEED), the International Federation of Engineering Education Societies (IFEES), United Nations Education, Science, and Community Organization (UNESCO), the Latin American and Caribbean Consortium of Engineering Institutes (LACCEI), members of the Science and Technology in Society Forum (STS Forum), and the Global Engineering Deans Council (GEDC).

\section{A. Landscape of Global Challenges and Goals}

There has not been a comprehensive collection and review of global initiatives on grand challenges, thus our research is an attempt to fill this dearth so that we might better understand intersections and engagement by various stakeholders. After an extensive review of literature to determine identification of and engagement in grand challenges for our world's citizens, we find that there are research projects, foundations, and policy-driven initiatives that span across disciplines in the following timeline.

\footnotetext{
Millennium Project Global Challenges for Humanity - 1999

Gates Foundation Grand Challenges in Global Health - 2003

Clinton Global Initiative - 2005

NAE Grand Challenges in Engineering for the 21st Century - 2008

USAID Grand Challenges for Development - 2011
} 
TED MED Great Challenges - 2012

Obama White House 21st Century Grand Challenges - 2013

World Climate Research Programme Grand Challenges - 2013

UN Sustainable Development Goals - 2015

National Academy of Medicine (NAM) Grand Challenges in Health and Medicine - 2016

World Economic Forum Deep Shift Technologies - 2015

American Academy of Social Work \& Social Welfare,12 Grand Challenges for Social Work 2016

In the review of the global initiatives and in the deeper exploration of the GCs and the SDGs, thought leaders recognize the crucial integration of diverse perspectives and disciplines into solving these complex issues. If indeed a main goal of education is to engage and prepare our students to be future leaders and effective members of their communities, we need to provide opportunities for meaningful experiences and reflection about how the abstract concepts they learn in courses apply to the real world. We assert that this can be effectively done through experiential learning. The UN recognizes that the SDG aim of ending poverty must incorporate strategies that build economic growth while addressing a range of social needs including education, health, social protection, and job opportunities, while tackling climate change and environmental protection.

\section{B. Example of UNESCO's Focus on Specific SDGs to Address Gender Equity}

Organizations such as UNESCO are continuing to seek ways to encourage organizations to consider the SDGs, and the entity is connecting specific SDGs to its work with various groups. A strong example includes the way that UNESCO's engineering program is focusing on SDG 4 and SDG 5. SDG 4 - Quality Education - notes that girls and boys need to have access to affordable and quality technical, vocational and tertiary education, including university. SDG 5 - Gender Equity - effective participation of equal opportunities for leadership at all levels of decision making in political, economic, and public life. With a focus on SDG 5, Gender Equity: Achieve gender equality and empower all women and girls, in 2017, UNESCO launched the One Million Girls in STEM campaign with WomEng, a top Non-governmental Organization (NGO) in South Africa, founded to address the issues facing women in the engineering sector from school level all the way through to industry. WomEng's "One Million Girls in STEM" campaign is an initiative to get at least one million girls around the world, specifically in Africa and developing countries, involved in STEM activities over the next 10 years. WomEng has already reached out to 10,000 girls in STEM in Africa. In the next 10 years, having developed robust and scalable programs, WomEng, together with UNESCO, has set the goal to impact 1 million girls through the STEM education around the world, with a strong emphasis on Africa. 
On March 9, 2018, UNESCO's Paris office, along with WFEO, organized a symposium on "Women Engineers: Empowering Rural Women and Girls." The symposium provided the audience with an opportunity to examine the underrepresentation of women in engineering, and to consider ways that engineering solutions could be employed to improve the lives of rural women and girls, in line with the SDGs and successful case-studies of women in engineering. As a follow-up to this meeting, and in keeping with the goal of expanding the conversation set forth at the 2017 meeting for Engineering Report II in Beijing, UNESCO convened a session on March 21, 2018, to discuss the connection between SDG 5 and other goals in on women in rural areas. This side event of the sixty-second session of the Commission on the Status of Women, "Empowering Rural Women in Engineering Fields," was held at the United Nations

Headquarters in New York. This session was a focused discussion of the SDGs and the GCs, and included representatives from WCCE, WomEng, the Society of Women Engineers (SWE), Purdue University, Elsevier (global information analytics) and UMBC.

For the March 21, 2018 discussion on empowering women and girls in rural areas, the speakers discussed ways that women from these areas can be encouraged to consider engineering research and projects. As an example, discussion included some of the SDGs that connect to research in rural areas such as:

- SDG 6: Clean water and sanitation - access to safe and affordable drinking water, equitable sanitation and hygiene, improving water quality and reducing pollution.

- SDG 14: Life Below Water - with targets to reduce marine pollution, manage and protest marine and coastal ecosystems, and regulate harvesting and overfishing - particularly where there are populations that depend on marine biodiversity.

- SDG 15: Life on Land - where the targets include conservation and restoration of forests and wetlands, reduction of degradation of natural habitats.

\section{Sample Intersections of SDGs and GCs}

STEM-based broadening participation programs for the University System of Maryland led by the University of Maryland Baltimore County (UMBC) such as PROMISE: Maryland's Alliance for Graduate Education and the Professoriate (AGEP), and the Louis Stokes Alliance for Minority Participation's undergraduate LSAMP and graduate student LSAMP Bridge to the Doctorate (LSAMP-BD) programs are beginning to expose students to the SDGs and the GCs through participation in conferences such as WEEF, LACCEI, and SPEED. Further, discussion is started to take place in locally in Maryland with both the SDGs and the GCs were presented together at the USM's 2017 PROMISE Summer Success Institute (SSI). Following the 2017 SSI, there was discussion among the authors of this paper regarding intersections that were observed within the activities of either the LSAMP or the PROMISE AGEP. As a start, the following intersections were considered. 
- The PROMISE AGEP's mission to increase the numbers of diverse faculty in STEM led to the intersected goal/challenge to Include Diverse Science and Engineering Faculty: The Multipliers. This provided an opportunity to intersect SDG 4: Quality Education, SDG 5: Gender Equity, GC1: Advance Personalized Learning, and GC 14: Engineers the Tools of Scientific Discovery.

- The LSAMP undergraduate and LSAMP Bridge to the Doctorate programs goal/challenge to Engage Students in SPEED's International Team Projects led to immersion experiences in different countries and interaction with the international Student Platform for Engineering Education Development (SPEED). The students worked on projects that tackled clean water in urban communities, which led to the intersection of SDG 6: Clean Water and Sanitation, SDG 11: Sustainable Cities and Communities, and GC 7: Restore and Improve Urban Infrastructure.

Maryland's AGEP and LSAMP programs will continue to consider exposure to the SDGs and GCs as catalysts that can increase interest and retention in engineering. In 2018, delegations from Maryland will attend the LACCEI conference in Peru to work with SPEED to further consider the GCs and SDGs in meaningful projects. They will also engage in the "Peace Engineering" conference of the World Engineering Education Forum (WEEF) later in 2018 in New Mexico.

Just as the UN SDGs beckon for interdisciplinary engagement, the NAE also recognizes that to face and solve the GC, not only must there be a feasible engineering solution, but it must be economically viable and socially desirable. We posit that the structure of the GCSP creates cocurricular opportunities for experiential learning that can be adapted to any discipline, not just engineering, so that the UN SDGs and other global initiatives in our timeline, can be effectively integrated into educational systems around the world.

\section{Recommendations}

This paper recommends more conversation between stakeholders who are working with the GCs and the SDGs. An example is the student organization SPEED, Student Platform for Engineering Education Development which teamed with BEST, the Board of European Students of Technology, to produce a study initiated by Dassault Systems, and supported by the International Federation of Engineering Education Societies (IFEES) and the Global Engineering Deans Council (GEDC). While the SPEED and BEST reports focus on students' responses to the GCs, SPEED's Global Student Forum focuses on projects that draw attention to the SDGs, suggesting that the organization is well-aware of both. UNESCO's upcoming project for 2019, Engineering Report II, will provide an opportunity for engineering communities from around the world to come together to collaborate on understandings of the SDGs, and ways that the GCs connect. The Kick-off Meeting (Current and Future Trends in Engineering Around the World) was held in 
Beijing, China in September 2017. The meeting connected researchers and contributors from Scotland, Denmark, Paris, Jakarta, China, the US, and other locales. In addition, the meeting included international engineering organizations, an international academy of engineering, universities, and a ministry of education. The meeting also included an International Knowledge Centre, which has international exchanges and cooperation with Canada, USA, Dominican Republic, Colombia, Peru, Czech Republic, France, Switzerland, Iran, United Arab Emirates, China, Malaysia, Japan, Indonesia, and Australia. Such connections will be used to assist UNESCO with including perspectives from around the world for this next Engineering Report.

Additional recommendations for promoting exposure to the GCs and SDGs include:

- Include engineering research areas and projects within coursework that will showcase how the GCs and SDGs will serve humanity.

- Expose more women and people from underrepresented groups to the GCs and SDGs, with discussions about ways that projects can assist with humanitarian efforts.

- Work with professors to share new topics so that the premise of the GCs and SDGs can be tied to engineering research and projects

- In the same way that the NAE has developed Grand Challenges Scholars, commit to developing a new generation of researchers who will be focused on projects that will include the GCs, and move the targets of the SDGs.

There is room for expanded conversation and interaction at meetings of ASEE, SEFI, LACCEI, SPEED, and others. We recommend that leaders of the organizations be ready and open to facilitating such discussions, with specific attention to connecting the SDGs and GCs for humanitarian action on behalf of the engineering community.

\section{Next Steps and Conclusion}

Next steps include completing the survey, focus groups from the NAE GCSP and their K-12 Partner Programs, GC Summit attendees, the Student Platform for Engineering Education Development (SPEED), the International Federation of Engineering Education Societies (IFEES), United Nations Education, Science, and Community Organization (UNESCO). It will also include the Latin American and Caribbean Consortium of Engineering Institutes (LACCEI), members of the Science and Technology in Society Forum (STS Forum), and the Global Engineering Deans Council (GEDC), and the interviews for this study.

Following receipt of responses, we will analyze our methods and the findings to create a visual analysis of the intersections of GC and SDG. The research team will analyze data about how experiential learning impacts the engagement and perceptions these global initiatives on 
university-based curricular and co-curricular opportunities for students. We are looking to expand and support this work with funding specific to the task, and anticipate that the results of this research will inform engineering educators and the broader global community interested in ways that communities are engaging in our most pressing issues of modern time. Understanding complex aspects of the intersections and aspects of engagement may inform new action plans for universities and other stakeholders to take in meeting these goals.

\section{Acknowledgements}

Author Renetta Tull acknowledges the PROMISE Engineering Institute, which supported her participation in the 2017 World Engineering Education Forum in Malaysia. The PROMISE Engineering Institute is sponsored by the National Science Foundation's Engineering Directorate, EEC Division of Engineering Education and Centers grant award \#1734741. In seeking new ways to engage underrepresented minority (URM) undergraduate students' interest in pursuing advanced engineering careers, and particularly careers as professors, Tull has introduced the SDGs and GCs to graduate students within the PROMISE Alliance for Graduate Education and the Professoriate (AGEP). This effort has informed this work, and is supported by NSF/EHR/HRD grant awards: "Collaborative Research: AGEP - T: PROMISE AGEP Maryland Transformation” \# 1309290, \#1309264, and \#1309256. SDGs and GCs have also been introduced to undergraduate student participants within the USM's Louis Stokes Alliance for Minority Participation (LSAMP) - NSF \#1619676, and the LSAMP Bridge to the Doctorate Program at the University of Maryland Baltimore County (UMBC) - NSF \#1500511. Tull also acknowledges the UMBC College of Engineering and IT, and The Graduate School at UMBC for in-kind time and effort support to pursue this research and participate in activities sponsored by the United Nations Educational, Scientific and Cultural Organization (UNESCO).

\section{References}

[1] W. Cobern. Socio-cultural perspectives on science education: An international dialogue. Dordrecht, The Netherlands: Springer Publishing, 1998.

[2] J. S. Eccles. Where are all the women? Gender differences in participation in physical science and engineering. In S. J. Ceci \& W. M. Williams (Eds.), Why aren't more women in science? Top researchers debate the evidence (pp. 199-212). Washington, DC: American Psychological Association, 2007.

[3] M. Greene. Self-consciousness in a technological world. Retrieved 3 January 2008 from www.pocketknowledge.tc.edu. n/a 1965-2008.

[4] L. Lee \& D. Wilson. Empowering the engineering undergraduate in an era of economic globalization, Frontiers in Education Conference: Indianapolis, Indiana, 2005.

[5] J. Leydens. The problem of knowledge in incorporating humanitarian ethics in engineering education: Barriers and opportunities. Annual ASEE/IEEE Frontiers in Education Conference, 2003. 
[6] National Academy of Engineering Committee on Public Understanding of Engineering Messages. Changing the conversation. National Academy Press, 2008.

[7] C. White. Taking HEED: Intersections of Women's Lives with Humanitarian Engineering Experiences and Design. AERA Annual Conference, 2013.

[8] National Society of Professional Engineers. Engineers' creed. Retrieved 1 September 2008 from http://www.nspe.org/Ethics/CodeofEthics/Creed/creed.html., 1954.

[9] L. Vanasupa, K. C. Chen, \& L. Slivovsky. Global Challenges as Inspiration: A Classroom Strategy to Foster Social Responsibility. SCI ENG ETHICS 12: 373. https://doi.org/10.1007/s11948-006-0036-5, 2006.

[10] C. White, A. Talley, C. Crawford, and K. Wood. Interests and Influences in Humanitarian Engineering. ASEE Annual Conference, 2010.

[11] D. Hastings and C. White. Beyond the Engineer of 2020. World Engineering Education Forum, 2014.

[12] Partnership for 21st Century Skills . Global challenges as inspiration: A classroom strategy to foster social responsibility. Science and Engineering Ethics 12(2), 373-380, 2002.

[13] J. Dewey. Democracy and education: An introduction to the philosophy of education. New York: Macmillan 1916/1944.

[14] M. E. Madden, M. Baxter, H. Beauchamp, K. Bouchard, D. Habermas, M. Huff, B. Ladd, J. Pearon, and G. Plague. Rethinking STEM education: An interdisciplinary STEAM curriculum. Procedia Computer Science 20, 541-546, 2013.

[15] M. H. Koomen, S Weaver, R. B. Blair, and K. Oberhauser. "Disciplinary Literacy in the Science Classroom: Using Adaptive Primary Literature.," Journal of Research in Science Teaching., v.53, 2016, p. 847, 2016.

[16] H. Kobori, J. L. Dickinson, I. Washitani, R. Sakurai, T. Amano, N. Komatsu, W Kitamura, S. Takagawa, K. Koyama, T. Ogawara, and A. J. Miller-Rushing. "Citizen science: A new approach to advance ecology, education, and conservation," Ecological Research, v.31, 2016, p. 1-19, 2016.

[17] National Academy of Engineering, The engineer of 2020: visions of engineering in the new century.

Washington, DC: National Academies Press, 2004.

[18] National Academy of Engineering, Educating the engineer of 2020: adapting engineering education to the new century. Washington, DC: National Academies Press, 2005.

[19] T. Katsouleas, R. Miller, and Y. Yortos, "The NAE Grand Challenges Scholars Program," The Bridge, vol. 43, no. 2, pp. 53-56, Summer 2013.

[20] J. Lucena, G. Downey, B. Jesiek, and S. Elber, "Competencies beyond countries: The re-organization of engineering education in the United States, Europe, and Latin America," J. of Eng. Educ., vol. 97, no. 4, pp. 443447, Oct. 2008. 
[21] J. J. Duderstadt and U. of M. M. Project, Engineering for a Changing World: A Roadmap to the Future of Engineering Practice, Research, and Education. Millennium Project, University of Michigan, 2008.

[22] National Academy of Engineering, Changing the conversation: messages for improving public understanding of engineering. Washington, D.C: National Academies Press, 2008.

[23] National Academy of Engineering. Messaging for engineering: from research to action. Washington, D.C: National Academies Press, 2013.

[24] G. L. Downey, J. C. Lucena, B. M. Moskal, R. Parkhurst, T. Bigley, C. Hays, B. K. Jesiek, L. Kelly, J. Miller, S. Ruff, J. L. Lehr, and A. Nichols-Belo, "The Globally Competent Engineer: Working Effectively with People Who Define Problems Differently,” J. Eng. Educ., vol. 95, no. 2, pp. 107-122, 2006.

[25] D. A. Kolb, Experiential learning: Experience as the source of learning and development. FT press, 2014.

[26] S. Pingree, R. Hawkins, and R. Botta, R. The effect of family communication patterns on young people's science literacy. Science Communication, 22(2), 115-132, 2000.

[27] C. White, R. G. Tull, R. Sigamoney, Y. Zastavker. Exploring Intersections of Global Grand Challenges and Sustainable Development Goals. World Engineering Education Forum, 2017. 